(6)

\title{
Evaluation of an anthropomorphic male pelvic phantom for image-guided radiotherapy
}

This article was published in the following Dove Press journal:

Reports in Medical Imaging

23 July 2009

Number of times this article has been viewed

\author{
B Schaly' \\ V Varchena ${ }^{2}$ \\ $\mathrm{PAu}{ }^{3}$ \\ G Pang 3,4 \\ 'Grand River Regional Cancer Centre, \\ Kitchener, ON, Canada; ${ }^{2} \mathrm{CIRS}$ Inc., \\ Norfolk, VA, USA; ${ }^{3}$ Odette Cancer \\ Centre, Toronto, ON, Canada; \\ ${ }^{4}$ Departments of Radiation Oncology \\ and Medical Biophysics, University of \\ Toronto, Toronto, ON, Canada
}

\begin{abstract}
Soft-tissue imaging in the treatment room is one of the main challenges faced today in high precision radiotherapy. The objective of this work is to evaluate a new anthropomorphic male pelvic phantom (CIRS Inc., Norfolk, VA, USA) that can be used in a radiotherapy department to assess the ability of an X-ray imaging system for imaging soft-tissue targets in the treatment room. To this end, we evaluated the tissue-equivalency of the phantom materials in terms of the linear attenuation and energy absorption coefficients. X-ray computed tomography (CT) images of the phantom were also obtained and compared with that of patients. Our results demonstrated that the male pelvic phantom is a good representation of actual prostate cancer patients and can be a valuable tool for image-guided radiotherapy.
\end{abstract}

Keywords: image-guided radiotherapy, X-ray imaging, anthropomorphic phantom

PACS numbers: $87.56 . \mathrm{Fc}, 87.59 . \mathrm{bd}$, 87.85.Lf

\section{Introduction}

Imaging of soft-tissue targets, such as the prostate, in the treatment room is one of the main challenges faced today in high precision radiotherapy. ${ }^{1}$ Different $\mathrm{X}$-ray imaging systems including kilovoltage $(\mathrm{kV})^{2}$ and megavoltage $(\mathrm{MV})^{3-5} \mathrm{X}$-ray systems have been developed to locate soft-tissue targets just before or during the radiotherapy treatment. Currently, there is a lack of tools that can be used in a clinic to quickly assess the ability of these X-ray imaging systems for imaging soft-tissue targets before these systems are used on patients. Although contrast-detailed phantoms ${ }^{6}$ have been commonly used during acceptance and subsequent quality assurance tests of an X-ray imaging system, they do not directly provide information on whether the imaging system is capable of imaging soft-tissue targets in patients. In principle, volunteer patients could be used to directly assess the imaging system for soft-tissue imaging, but this method is time-consuming, inconvenient, and associated with unnecessary radiation exposure. A direct and convenient way of assessment is to use an anthropomorphic phantom. However, the commonly used Alderson-Rando ${ }^{7}$ and ATOM dosimetry ${ }^{8}$ phantoms in radiotherapy departments do not contain most of the soft-tissue organs, such as the prostate, which is a common target in radiotherapy. Thus, there is a clinical need for a new anthropomorphic phantom that contains soft-tissue organs for image-guided radiotherapy applications.

Recently, a new anthropomorphic male pelvic phantom (CIRS Inc., Norfolk, VA, USA) was developed, which consists of the complete set of human male cross-sectional anatomy in the pelvic region. The purpose of this work is to evaluate the new phantom to determine if this phantom is a realistic representation of actual prostate cancer
Correspondence: Geordi Pang Odette Cancer Centre, 2075 Bayview Avenue, Toronto, ON M4N 3M5, Canada $\mathrm{Fax}+$ I 416480680 I

Email geordi.pang@sunnybrook.ca 
patients and thus can be used as a substitute for a real prostate patient for image-quality assessment. We verify the tissueequivalency of the phantom materials for X-ray imaging by (1) calculating the linear attenuation and energy absorption coefficients based on the elemental compositions of the phantom materials in comparison with that of body tissues; (2) directly measuring the linear attenuation coefficients using a ${ }^{60} \mathrm{Co}$ source to verify the calculations. X-ray computed tomography (CT) images of the phantom are shown and compared with that of prostate cancer patients. A clinical example on the use of the phantom is also included.

\section{Methods and materials}

\section{Phantom design}

The anthropomorphic design of the pelvic phantom was based on the Visible Human Project (US National Library of Medicine, Washington, DC, USA). ${ }^{9}$ Soft tissue organs were rendered from the axial cryosections (color slides with $2048 \times 1216$ pixels at $1 \mathrm{~mm}$ interval). Bone anatomy that included trabecular and cortical bone together, spinal discs, cartilage and spinal cord were rendered from the axial CT images $(512 \times 512$ pixels at $1 \mathrm{~mm}$ interval $)$. The Visible Human Project represents a human male that is much larger than average and the original data set was rescaled to $90 \%$ in an axial plane and to $95 \%$ in the vertical (superior-inferior) dimension before rendering. All the patterns were built using stereolithography from the organ surface files (US Patent pending). Molds were manufactured from the patterns and poured with the tissue-equivalent resins. Then, all the organs and tissues were assembled together and encapsulated in adipose equivalent material. Figure 1 shows the phantom at completion and before the adipose material was added. The physical dimensions of the phantom are $\sim 20 \mathrm{~cm}$ anterior-posterior separation at
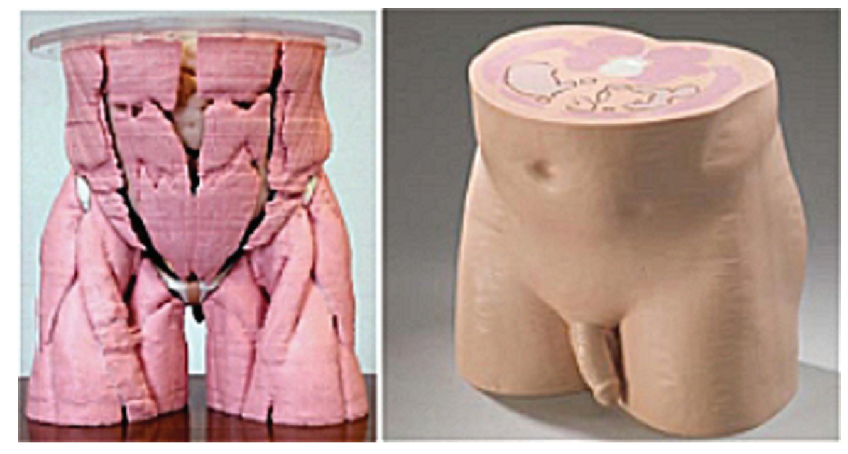

Figure I Picture of the phantom: (left) muscle structure with underlying organs; (right) finished product. the prostate region, $\sim 30 \mathrm{~cm}$ separation laterally at that point, and about $38 \mathrm{~cm}$ in the vertical dimension, where the extent is from the lower abdomen to the upper leg. The phantom weighs $\sim 55 \mathrm{lbs}$. The elemental compositions of the tissue-equivalent resins are given in Table $1 \mathrm{~A}$. The material to mimic a bladder was a mix of the bladder wall and the urine content. Bone-equivalent material represented an "average" bone that consists of a mix of cortical and trabecular bones. We note that the elemental compositions of the tissue-equivalent resins are not exactly the same as that of body tissues reported in Woodard and White ${ }^{10}$ and the Reference Man. ${ }^{11}$ However, the differences in electron density (Table 1B) and linear attenuation coefficients (see below) between body tissues and tissue-equivalent resins are very small $(\sim 0.5 \%$ or less).

\section{Tissue-equivalency of phantom constituents}

A convenient way of comparing radiation characteristics of a tissue with that of a substitute for X-ray imaging is to consider the linear attenuation coefficients $\mu$ and the energy absorption coefficients $\mu_{e n}$. These two quantities can be derived from ${ }^{12}$

$$
\begin{gathered}
\mu=\rho \sum_{i} \omega_{i}(\mu / \rho)_{i} \\
\mu_{e n}=\rho \sum_{i} \omega_{i}\left(\mu_{e n} / \rho\right)_{i}
\end{gathered}
$$

for a tissue or a tissue substitute, where $\omega_{i}$ is the proportion, by mass, of the $i$ th element with the corresponding mass attenuation coefficient $(\mu / \rho)_{i}$ or the mass energy absorption coefficient $\left(\mu_{e n} / \rho\right)_{i}$, and $\rho$ is the density of the tissue or

Table IA Elemental compositions of tissue-equivalent materials used in the phantom

\begin{tabular}{ll}
\hline Tissue-equivalent resins & $\begin{array}{l}\text { Elemental compositions } \\
\text { (\% by mass) }\end{array}$ \\
\hline Prostate & $\mathrm{C}(55.80), \mathrm{O}(25.90), \mathrm{H}(7.44)$, \\
& $\mathrm{N}(2.24), \mathrm{Mg}(8.4 \mathrm{I}), \mathrm{Cl}(0.20)$ \\
Bladder & $\mathrm{C}(5 \mathrm{I} .8 \mathrm{I}), \mathrm{O}(28.22), \mathrm{H}(7.73)$, \\
& $\mathrm{N}(\mathrm{I} .68), \mathrm{Mg}(\mathrm{I} 0.30), \mathrm{Cl}(0.20)$ \\
Adipose & $\mathrm{C}(69.80), \mathrm{O}(\mathrm{I} 6.63), \mathrm{H}(\mathrm{I} 0.05)$, \\
& $\mathrm{N}(\mathrm{I} .63), \mathrm{Mg}(\mathrm{I} .65), \mathrm{Cl}(0.18)$ \\
Muscle & $\mathrm{C}(54.60), \mathrm{O}(25.73), \mathrm{H}(8.33)$, \\
& $\mathrm{N}(\mathrm{I} .49), \mathrm{Mg}(9.63), \mathrm{Cl}(0.18)$ \\
Intestine & $\mathrm{C}(55.80), \mathrm{O}(26.20), \mathrm{H}(8.07)$, \\
& $\mathrm{N}(\mathrm{I} .78), \mathrm{Mg}(7.90), \mathrm{Cl}(0.20)$ \\
Average bone & $\mathrm{C}(37.03), \mathrm{O}(35.66), \mathrm{H}(4.83)$, \\
& $\mathrm{N}(0.97), \mathrm{Ca}(\mathrm{I} 5.24), \mathrm{Mg}(6.19), \mathrm{Cl}(0.05)$ \\
\hline
\end{tabular}


Table IB Electron density of phantom materials (CIRS) as compared to that of real body tissues ${ }^{10,11}$

\begin{tabular}{|c|c|c|c|}
\hline Tissue type & 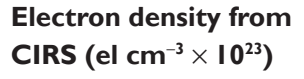 & $\begin{array}{l}\text { Electron density } \\
\left(\mathrm{el} \mathrm{cm}^{-3} \times 10^{23}\right)\end{array}$ & $\begin{array}{l}\text { Ratio } \\
\text { (CIRS/Reference) }\end{array}$ \\
\hline Prostate & 3.476 & 3.455 & 1.006 \\
\hline Bladder & 3.449 & 3.430 & 1.006 \\
\hline Adipose & 3.179 & 3.180 & 1.000 \\
\hline Muscle & 3.498 & 3.478 & 1.006 \\
\hline Intestine & 3.447 & 3.424 & 1.007 \\
\hline Average bone & 5.030 & 5.035 & 0.999 \\
\hline
\end{tabular}

tissue substitute. We note that Eqs. (1A) and (1B) pertain to isolated neutral atoms and do not take into account any molecular effect that may exist at low X-ray energies. The quantities $(\mu / \rho)_{i}$ and $\left(\mu_{e n} / \rho\right)_{i}$ as a function of X-ray energies for all elements $(Z=1$ to 92$)$ can be found in Hubbell and Seltzer. ${ }^{13}$ We calculated $\mu$ and $\mu_{e n}$ for the phantom materials listed in Table 1A in comparison with the linear attenuation and energy absorption coefficients of the corresponding body tissues calculated based on their elemental compositions given in Woodard and White ${ }^{10}$ and the Reference Man. ${ }^{11}$

In order to verify the theoretical calculations, we directly measured the linear attenuation coefficients for a number of uniform samples (one for each phantom material) provided by CIRS Inc. These samples were cylindrically shaped with identical dimensions (10 cm diameter and $5 \mathrm{~cm}$ thickness). The physical density of each sample was measured by using vernier calipers and a digital mass scale with the uncertainty of measurement estimated to be $\pm 0.001 \mathrm{~g} / \mathrm{cm}^{3}(\sim 0.1 \%)$.

The linear attenuation coefficients of these samples were measured using a cobalt treatment unit (Theratron 780C; Theratronics, Kanata, ON, Canada) with a narrow beam since the photon energy spectrum of a cobalt source is known and much simpler than that of a linear accelerator (LINAC) or a kV X-ray tube. Figure 2 shows the experimental setup for measuring photon transmission through a uniform sample of each phantom material to determine its linear attenuation coefficient. To validate the experimental setup, we replaced the sample with an aluminum block of thickness $\sim 3.9 \mathrm{~cm}$ and compared the measured with the known attenuation coefficient for aluminum, ${ }^{14}$ where the difference between the measured and the reference value was found to be $<1 \%$.

The cobalt beam is nearly monoenergetic with two characteristic $\gamma$-ray energies that are emitted with equal proportions. However, since scattered radiation from the head of the unit will contribute to the energy spectrum, these lower energy photons had to be blocked as much as possible. We used four lead blocks to assimilate the $\mathrm{X}$ and $\mathrm{Y}$ jaws on a treatment machine placed as closely as possible to the head of the unit, since the minimum field size on the unit is $4.5 \times 4.5 \mathrm{~cm}^{2}$. These blocks were roughly $12 \times 12 \times$ $5.5 \mathrm{~cm}^{3}$ each, and the total thickness of the collimator along the beam direction is $>20$ half value layers $\left(1.1 \mathrm{~cm}\right.$ for $\left.{ }^{60} \mathrm{Co}\right)$.

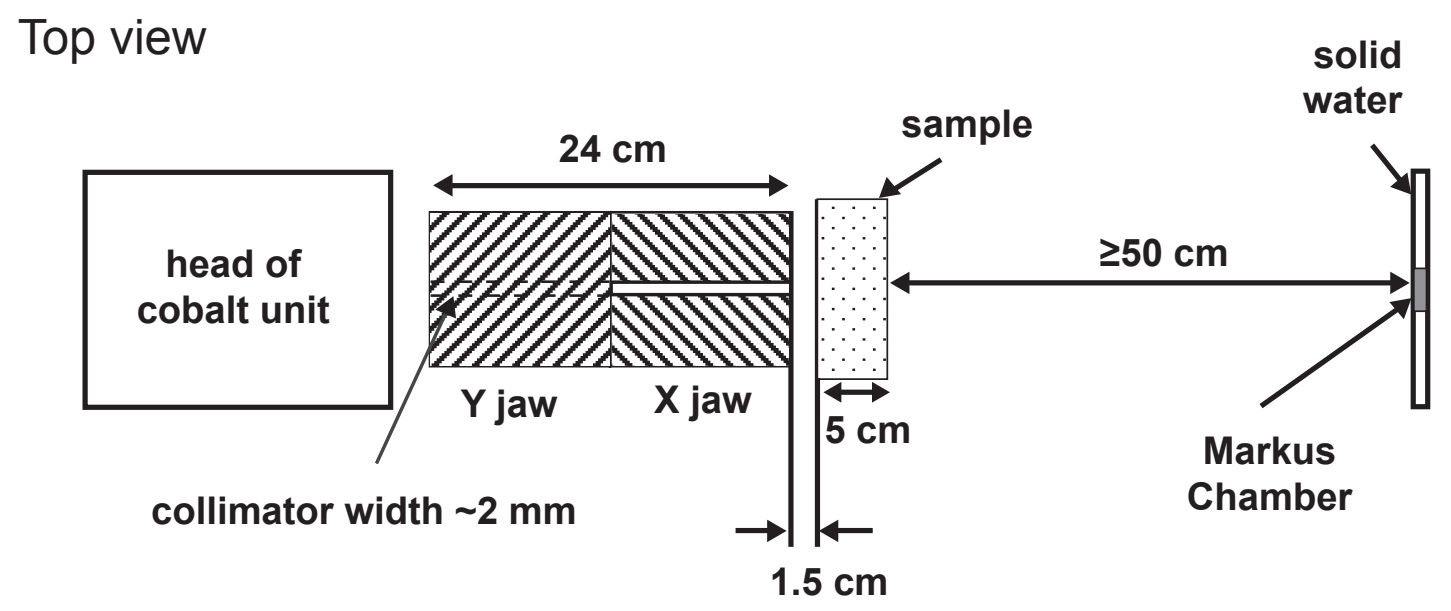

Figure 2 Experimental setup for the measurement of attenuation coefficients of the tissue-equivalent samples (ie, the components of the pelvis phantom). Cobalt unit settings: gantry angle, $270^{\circ}$; couch angle, $270^{\circ}$; collimator angle, $0^{\circ}$; field size, $4.5 \times 4.5 \mathrm{~cm}^{2}$. 
The Y jaws were opened by placing $\sim 3 \mathrm{~mm}$ thick cardboard pieces between the lead blocks. The $\mathrm{X}$ jaws were pushed together as closely as possible $(2 \mathrm{~mm})$ while considering the magnitude of the expected signal in the detector (Markus ion chamber and PTW Unidos-E electrometer), which should be much larger than the reading from cable leakage and room scatter. The room scatter signal is measured by closing the lead collimators thus blocking the entire beam. The gantry, couch and collimator angles on the cobalt unit were set to $270^{\circ}, 270^{\circ}$, and $0^{\circ}$, respectively. The phantom samples were placed at about $1.5 \mathrm{~cm}$ away from the lead collimator. A piece of Solid Water with a Markus ion chamber insert was placed $\geq 50 \mathrm{~cm}$ away from the phantom in order to minimize the amount of scattered photons (generated in the sample) reaching the ion chamber. ${ }^{15,16}$ The electrometer reading from each sample, $I$, is normalized to the measurement with no phantom present, $I_{0}$. Then, the measured linear attenuation coefficient, $\mu_{m}$, can be determined by using

$$
\mu_{m}=-\frac{1}{x} \ln \left(\frac{I-I_{b}}{I_{0}-I_{b}}\right)
$$

where $x$ is the thickness of the sample and $I_{b}$ is the background signal based on room scatter. We performed three independent measurements on different days to verify the reproducibility of the results and to reduce experimental error. Furthermore, each trial consisted of short, intermediate and long data acquisition times. The short acquisition time consisted of a 1 min charge reading with no phantom and $1 \mathrm{~min}$ with the phantom in the beam, for three measurements. The intermediate counting time consisted of two measurements of 2 min for each sample in the radiation beam and for no sample present. The long counting time consisted of one measurement for $6 \mathrm{~min}$ for each sample in the beam and for no sample. The measured value $\mu_{m}$ for each sample was determined from Eq. (2) and averaged over all trials.

The measured, narrow-beam linear attenuation coefficient for each phantom material was then compared to the calculated value $\mu_{\text {spec }}$ for the phantom material at ${ }^{60} \mathrm{Co}$ energies, where $\mu_{\text {spec }}$ was obtained using Eq. (1A) and averaged over the two characteristic energies of ${ }^{60} \mathrm{Co}$ decay, namely 1.17 and $1.33 \mathrm{MeV}$ energies (equally weighted).

\section{Comparison of phantom to patient data}

In order to determine how accurate the finished phantom product represents a real patient, the pelvic phantom was scanned with a CT simulator (GEMINI; Philips Medical Systems, Inc., Cleveland, OH, USA) at $120 \mathrm{kVp}$ and $250 \mathrm{~mA}$, and a slice thickness of $2.5 \mathrm{~mm}$. The CT images were transferred to the Pinnacle treatment planning system (v. 7.6c Philips, Madison, WI, USA). The CT images of the phantom were compared to CT images of randomly selected prostate cancer patients from Odette Cancer Centre with similar scanning parameters (120 kVp, 250 mA, 3 mm slice thickness). It should be noted that no contrast was administered in the bladder and that these patients did not receive any specific instructions prior to the scan (eg, bladder filling). One observer (BS) contoured the prostate, seminal vesicles, rectum and bladder in the patients and the phantom to avoid inter-observer variations. The mean and standard deviation of the CT number in Hounsfield units $(\mathrm{HU}){ }^{17}$ were obtained for the phantom and patient CT images in regions of interest of varying area, depending on the structure. For example, for cortical bone and bladder wall, the area of the region of interest was $\sim 0.05 \mathrm{~cm}^{2}$ (ie, only a few pixels). The CT number for the following materials was measured: prostate, bladder (wall and contents), intestine, muscle, fat, and bone (cortical and trabecular).

\section{Clinical application}

To demonstrate the usefulness of this phantom in a clinic, we evaluated a newly installed, clinical investigational MV conebeam CT (MV-CBCT) system (Siemens; Concord, CA, USA) at Odette Cancer Centre with the phantom and compared to that with a patient study. The MV-CBCT system consisted of MV X-ray source (6MV) on a LINAC and an X-ray flat panel detector (XDAS 1640 AG9; PerkinElmer, Waltham, MA, USA) attached to the LINAC to acquire cone-beam CT data by simultaneously rotating them around the object. MV-CBCT images of the pelvic phantom were obtained first, followed by a patient study. Ten patients undergoing prostate radiotherapy were imaged using the investigational MV-CBCT system on an Institution Review Board-approved protocol following patient consent. ${ }^{5}$ The MV-CBCT scan protocol was the same for both the phantom and the patients, and the imaging dose used for each scan was 12 monitor units $(\mathrm{MU})(1 \mathrm{MU}=1 \mathrm{cGy}$ dose to water at the LINAC isocenter at the standard calibration conditions). ${ }^{18}$ The phantom images were compared to that of patient images to determine if the quality of the phantom images, especially the visibility of the prostate, is a good indication of the quality of patient images obtained from the same imaging system.

\section{Results}

Tissue-equivalency of phantom constituents

Table 2 shows the measured physical density of the tissue equivalent samples in comparison with the manufactory's 
Table 2 Measured physical densities for the tissue-equivalent samples in comparison with the manufacturer's specifications (CIRS) and reference data ${ }^{10,11}$

\begin{tabular}{llll}
\hline Sample & $\begin{array}{l}\text { Measured physical } \\
\text { density }\left(\mathbf{g} / \mathbf{c m}^{3}\right)\end{array}$ & $\begin{array}{l}\text { Physical density } \\
(\mathbf{C I R S})\left(\mathbf{g} / \mathbf{c m}^{3}\right)\end{array}$ & $\begin{array}{l}\text { Physical density } \\
\left(\mathbf{g} / \mathbf{c m}^{\mathbf{3}}\right)\end{array}$ \\
\hline Prostate & 1.083 & 1.077 & 1.04 \\
Bladder & 1.072 & 1.067 & 1.03 \\
Adipose & 0.966 & 0.962 & 0.95 \\
Muscle & 1.079 & 1.076 & 1.05 \\
Intestine & 1.069 & 1.062 & 1.03 \\
Average bone & 1.592 & 1.600 & 1.58 \\
\hline
\end{tabular}

specifications and the reference data. ${ }^{10,11}$ The measured values agree with the specifications within $0.6 \%$, which in turn are $1 \%-3 \%$ higher than the reference data. The higher physical densities are not uncommon in similar resin products. For example, the densities of commonly used Solid Water (Gammex 457, Middleton, WI, USA) and Plastic Water (CIRS Inc., Norfolk, VA, USA) are $\sim 4 \%$ and $3 \%$ higher than that of real water, respectively. However, the tissue-equivalent resins matches the real body tissues very well in terms of electron density (Table 1B) as well as the linear attenuation and energy absorption coefficients, as shown below.

The calculated linear attenuation and energy absorption coefficients for the phantom materials in comparison to that of real body tissues are given in Tables 3A-B. It can be seen from Table 3 that the difference in linear attenuation and energy absorption coefficients between the real body tissues and the tissue-equivalent resins is, in general, very small $\left(\leq 0.5 \%\right.$ for $\mu$ and $\leq 0.6 \%$ for $\left.\mu_{e n}\right)$ for the X-ray energy range from $0.04 \mathrm{MeV}$ to $10 \mathrm{MeV}$ except at the very low energies $(\leq 0.05 \mathrm{MeV})$ the difference in energy absorption coefficients is slightly higher $(\sim 1-2 \%)$.

Figure 3 shows a plot of the measured linear attenuation coefficients (using ${ }^{60} \mathrm{Co}$ ) for different tissue-equivalent samples in comparison with the calculated values $\mu_{\text {spec }}$ (or CIRS spec in Figure 3). The data points represent an average of three measurements acquired with the different counting times, and the error bars are \pm 1 standard error of the mean. The root-mean-square (RMS) deviation between the calculated and the measured was also determined for each sample, and the mean deviation for all the samples was $1.3 \%$, with a maximum deviation of $1.7 \%$ (bone sample). However, the mean deviation between the different trials, ie, the reproducibility of the measurement, was $\sim 2 \%$. Thus, the measured value agrees with the calculation very well within the experimental uncertainties. The excellent agreement in the linear attenuation and energy absorption coefficients between phantom materials and real body tissues shown in Table 3 demonstrated the tissue equivalency of the phantom materials.

\section{Comparison of phantom to patient data}

Figure 4 shows CT images of the phantom and that of prostate cancer patients. Figures 4 (a-d) show comparison of axial slices through prostate, rectum and bladder, while Figure 4 (e) and (f) show comparison of axial slices through the intestines. Overall, the phantom is very realistic. The main difference is the solid bones. For kV imaging, artifacts due to photoelectric absorption in the solid bones are more pronounced in the bladder and at the bladder/prostate interface region (most apparent in Figure 4 (c)). Thus, kV CT numbers in this region will be underestimated. Also, the intestines are encased in a higher density material but this did not affect the CT number of intestine. In Figures 4 (a) and (b), the prostate and rectum are noticeably smaller in the phantom. The prostate volume in the phantom was $13.3 \mathrm{~cm}^{3}$, which is close to that of the Reference $\operatorname{Man}^{11}\left(15.4 \mathrm{~cm}^{3}\right)$. However, the average prostate volume in external beam radiation therapy patients is 4-6 times larger. ${ }^{19-22}$ The mean prostate volume determined from our randomly selected patient population was $51.4 \mathrm{~cm}^{3}$ (range $14.0-94.7 \mathrm{~cm}^{3}$ ). Although the prostate volume in the phantom is on the low side of this range, it should not present a problem for assessing the capability of an X-ray imaging system to image the prostate.

Table 4 summarizes the results for $\mathrm{CT}$ numbers within the phantom compared to measured CT numbers from a randomly selected patient population from our institution. Overall, the measured CT numbers in the phantom are in good agreement with the measured values in the patient population as well as the values given by the manufacturer. The main exceptions are the prostate, the trabecular bone and the bladder wall, where bladder and bone were designed as solid structures.

The value of $21 \mathrm{HU}$ in the prostate and bladder is the result of the artifacts caused by the bones. An estimate of 
Table 3A Calculated linear attenuation coefficients $\mu$ at different $X$-ray energies for the phantom materials (CIRS) in comparison with that of real-body tissues ${ }^{10,11}$

\begin{tabular}{|c|c|c|c|c|c|c|c|c|c|c|c|c|}
\hline \multirow{2}{*}{$\begin{array}{l}\text { Energy } \\
(\mathrm{MeV})\end{array}$} & \multicolumn{2}{|l|}{ Prostate } & \multicolumn{2}{|l|}{ Bladder } & \multicolumn{2}{|l|}{ Muscle } & \multicolumn{2}{|l|}{ Adipose } & \multicolumn{2}{|l|}{ Intestine } & \multicolumn{2}{|c|}{ Average bone } \\
\hline & $\mu\left(\mathrm{cm}^{-1}\right)$ & Ratio* & $\mu\left(\mathrm{cm}^{-1}\right)$ & Ratio*- & $\mu\left(\mathrm{cm}^{-1}\right)$ & Ratio* & $\mu\left(\mathrm{cm}^{-1}\right)$ & Ratio* & $\mu\left(\mathrm{cm}^{-1}\right)$ & Ratio* & $\mu\left(\mathrm{cm}^{-1}\right)$ & Ratio* \\
\hline 0.04 & 0.2767 & 0.996 & 0.2814 & 0.996 & 0.2809 & 0.996 & 0.2274 & 1.000 & 0.2722 & 0.995 & 0.7962 & 1.003 \\
\hline 0.05 & 0.2348 & 1.000 & 0.2365 & 1.000 & 0.2376 & 1.000 & 0.2016 & 1.000 & 0.2317 & 0.999 & 0.5431 & 1.002 \\
\hline 0.06 & 0.2133 & 1.002 & 0.2137 & 1.002 & 0.2154 & 1.002 & 0.1874 & 1.000 & 0.2108 & 1.002 & 0.4269 & 1.002 \\
\hline 0.08 & 0.1905 & 1.004 & 0.1900 & 1.004 & 0.1921 & 1.004 & 0.1710 & 1.000 & 0.1886 & 1.004 & 0.3262 & 1.001 \\
\hline 0.1 & 0.1722 & 1.005 & 0.1764 & 1.005 & 0.1786 & 1.005 & 0.1604 & 1.000 & 0.1756 & 1.005 & 0.2829 & 1.001 \\
\hline 0.15 & 0.1564 & 1.005 & 0.1554 & 1.005 & 0.1575 & 1.005 & 0.1424 & 1.000 & 0.1550 & 1.005 & 0.2348 & 1.001 \\
\hline 0.2 & 0.1424 & 1.005 & 0.1414 & 1.005 & 0.1433 & 1.005 & 0.1299 & 1.000 & 0.1411 & 1.005 & 0.2101 & 1.001 \\
\hline 0.3 & 0.1233 & 1.005 & 0.1224 & 1.005 & 0.1241 & 1.006 & 0.1127 & 1.000 & 0.1222 & 1.006 & 0.1800 & 1.001 \\
\hline 0.4 & 0.1103 & 1.006 & 0.1095 & 1.006 & 0.11111 & 1.006 & 0.1009 & 1.000 & 0.1094 & 1.006 & 0.1606 & 1.001 \\
\hline 0.5 & 0.1007 & 1.006 & 0.1000 & 1.006 & 0.1014 & 1.006 & 0.0921 & 1.000 & 0.0998 & 1.006 & 0.1464 & 1.001 \\
\hline 0.6 & 0.0931 & 1.006 & 0.0924 & 1.006 & 0.0937 & 1.006 & 0.0851 & 1.000 & 0.0923 & 1.006 & 0.1352 & 1.001 \\
\hline 0.8 & 0.0818 & 1.006 & 0.0812 & 1.006 & 0.0823 & 1.006 & 0.0748 & 1.000 & 0.0811 & 1.006 & 0.1187 & 1.001 \\
\hline I & 0.0735 & 1.006 & 0.0730 & 1.006 & 0.0740 & 1.006 & 0.0672 & 1.000 & 0.0729 & 1.006 & 0.1067 & 1.001 \\
\hline 1.25 & 0.0657 & 1.006 & 0.0653 & 1.006 & 0.0662 & 1.006 & 0.0601 & 1.000 & 0.0652 & 1.006 & 0.0954 & 1.001 \\
\hline 1.5 & 0.0598 & 1.006 & 0.0594 & 1.006 & 0.0602 & 1.006 & 0.0547 & 1.000 & 0.0593 & 1.006 & 0.0868 & 1.001 \\
\hline 2 & 0.0513 & 1.005 & 0.0510 & 1.005 & 0.0517 & 1.006 & 0.0469 & 1.000 & 0.0509 & 1.006 & 0.0747 & 1.001 \\
\hline 3 & 0.0412 & 1.005 & 0.0409 & 1.005 & 0.0415 & 1.005 & 0.0376 & 1.000 & 0.0408 & 1.005 & 0.0604 & 1.001 \\
\hline 4 & 0.0353 & 1.004 & 0.0351 & 1.004 & 0.0355 & 1.004 & 0.0321 & 1.000 & 0.0350 & 1.004 & 0.0521 & 1.001 \\
\hline 5 & 0.0314 & 1.003 & 0.0312 & 1.003 & 0.0316 & 1.003 & 0.0284 & 1.000 & 0.0311 & 1.003 & 0.0468 & 1.001 \\
\hline 6 & 0.0287 & 1.002 & 0.0285 & 1.002 & 0.0288 & 1.002 & 0.0259 & 1.000 & 0.0284 & 1.002 & 0.0431 & 1.002 \\
\hline 8 & $0.025 I$ & 1.000 & 0.0250 & 1.000 & 0.0252 & 1.000 & 0.0225 & 1.000 & 0.0248 & 1.000 & 0.0384 & 1.002 \\
\hline 10 & 0.0228 & 0.998 & 0.0228 & 0.998 & 0.0230 & 0.998 & 0.0204 & 1.000 & 0.0226 & 0.997 & 0.0356 & 1.002 \\
\hline 15 & 0.0199 & 0.994 & 0.0199 & 0.995 & 0.0200 & 0.995 & 0.0175 & 1.000 & 0.0196 & 0.993 & 0.0320 & 1.003 \\
\hline 20 & 0.0185 & 0.992 & 0.0185 & 0.992 & 0.0186 & 0.992 & 0.0161 & 1.000 & 0.0183 & 0.990 & 0.0306 & 1.003 \\
\hline
\end{tabular}

Notes: *Ratio of linear attenuation coefficient of CIRS sample to that of real-body tissues. ${ }^{10,11}$ Relative difference $(\%)=($ Ratio-I $) \times 100$.

CT numbers in regions of minimal artifacts is $33 \mathrm{HU}$ and $43 \mathrm{HU}$ for prostate and bladder, respectively, which is in good agreement with the manufactory's specifications and the patient data. Furthermore, the CT number for bladder wall measured in the patient population agrees well with the CT number for bladder provided by the manufacturer.

\section{Clinical application}

Figure 5 shows the MV-CBCT images of the phantom, in comparison with that of a prostate patient, ${ }^{5}$ in three principle planes through the center of the prostate obtained using the clinical investigational MV-CBCT system. More MV-CBCT patient images obtained with the same system have been published. ${ }^{5}$ It can be seen from Figure 5 that the MV-CBCT image quality in term of soft-tissue imaging is poorer than that of $\mathrm{kV} \mathrm{CT}$ and we can barely see the prostate on MV-CBCT, especially in the sagittal and coronal planes. This agrees with the conclusion of the patient study ${ }^{5}$ that with the current investigational system, it is difficult to visualize the prostate on MV-CBCT images for most of the patients. Thus, the images of the phantom gave a good indication on the quality of patient images. We note here that the bright rings seen in the transverse images in Figure 5 are image artifacts due to a limited field of view in that the imaging volume does not encompass the phantom or the patient's complete cross section.

\section{Discussion}

We have evaluated a new anthropomorphic male pelvic phantom for image-guided radiotherapy applications. The phantom has been shown to be a visual and quantitative representation of human data. However, further improvements could be made with respect to (1) the physical densities of phantom materials, which are currently $1 \%-3 \%$ higher than that of corresponding real body tissues; (2) the bladder, which is currently of uniform density throughout 
Table 3B Calculated linear absorption coefficients $\mu_{\mathrm{en}}$ at different X-ray energies for the phantom materials (CIRS) in comparison with that of real-body tissues 10,11

\begin{tabular}{|c|c|c|c|c|c|c|c|c|c|c|c|c|}
\hline \multirow{2}{*}{$\begin{array}{l}\text { Energy } \\
\text { (MeV) }\end{array}$} & \multicolumn{2}{|l|}{ Prostate } & \multicolumn{2}{|l|}{ Bladder } & \multicolumn{2}{|l|}{ Muscle } & \multicolumn{2}{|l|}{ Adipose } & \multicolumn{2}{|l|}{ Intestine } & \multicolumn{2}{|c|}{ Average bone } \\
\hline & $\mu_{\mathrm{en}}\left(\mathrm{cm}^{-1}\right)$ & Ratio* & $\mu_{\mathrm{en}}\left(\mathrm{cm}^{-1}\right)$ & Ratio* & $\mu_{\mathrm{en}}\left(\mathrm{cm}^{-1}\right)$ & Ratio* & $\mu_{\mathrm{en}}\left(\mathrm{cm}^{-1}\right)$ & Ratio* & $\mu_{\mathrm{en}}\left(\mathrm{cm}^{-1}\right)$ & Ratio* & $\mu_{\mathrm{en}}\left(\mathrm{cm}^{-1}\right)$ & Ratio* \\
\hline 0.04 & 0.0716 & 0.983 & 0.0769 & 0.985 & 0.0742 & 0.983 & 0.0435 & 1.001 & 0.0692 & 0.980 & 0.4689 & 1.003 \\
\hline 0.05 & 0.0438 & 0.990 & 0.0463 & 0.990 & 0.0451 & 0.989 & 0.0294 & 1.002 & 0.0425 & 0.988 & 0.2474 & 1.004 \\
\hline 0.06 & 0.0332 & 0.996 & 0.0345 & 0.995 & 0.0340 & 0.994 & 0.0244 & 1.001 & 0.0324 & 0.994 & 0.1526 & 1.004 \\
\hline 0.08 & 0.0270 & 1.002 & 0.0275 & 1.001 & 0.0275 & 1.000 & 0.0224 & 1.001 & 0.0266 & 1.001 & 0.0818 & 1.004 \\
\hline 0.1 & 0.0265 & 1.004 & 0.0266 & 1.004 & 0.0268 & 1.003 & 0.0231 & 1.000 & 0.0262 & 1.004 & 0.0595 & 1.003 \\
\hline 0.15 & 0.0287 & 1.005 & 0.0286 & 1.005 & 0.0290 & 1.005 & 0.0260 & 1.000 & 0.0285 & 1.006 & 0.0476 & 1.002 \\
\hline 0.2 & 0.0308 & 1.006 & 0.0307 & 1.006 & 0.0311 & 1.006 & $0.028 I$ & 1.000 & 0.0306 & 1.006 & $0.047 \mathrm{I}$ & 1.001 \\
\hline 0.3 & 0.0332 & 1.006 & 0.0330 & 1.006 & 0.0334 & 1.006 & 0.0303 & 1.000 & 0.0329 & 1.006 & 0.0488 & 1.001 \\
\hline 0.4 & $0.034 I$ & 1.006 & 0.0338 & 1.006 & 0.0343 & 1.006 & 0.0312 & 1.000 & 0.0340 & 1.006 & 0.0497 & 1.001 \\
\hline 0.5 & 0.0343 & 1.006 & $0.034 I$ & 1.006 & 0.0345 & 1.006 & 0.0314 & 1.000 & 0.0340 & 1.006 & 0.0499 & 1.001 \\
\hline 0.6 & 0.0342 & 1.006 & 0.0339 & 1.006 & 0.0343 & 1.006 & 0.0312 & 1.000 & 0.0339 & 1.006 & 0.0496 & 1.001 \\
\hline 0.8 & 0.0333 & 1.006 & 0.0331 & 1.006 & 0.0336 & 1.006 & 0.0305 & 1.000 & 0.0330 & 1.006 & 0.0483 & 1.001 \\
\hline I & 0.0322 & 1.006 & 0.0320 & 1.006 & 0.0325 & 1.006 & 0.0295 & 1.000 & 0.0320 & 1.006 & 0.0467 & 1.001 \\
\hline 1.25 & 0.0308 & 1.006 & 0.0306 & 1.006 & 0.0310 & 1.006 & 0.0282 & 1.000 & 0.0306 & 1.006 & 0.0446 & 1.001 \\
\hline 1.5 & 0.0295 & 1.006 & 0.0292 & 1.006 & 0.0297 & 1.006 & 0.0270 & 1.000 & 0.0292 & 1.006 & 0.0427 & 1.001 \\
\hline 2 & $0.027 \mid$ & 1.006 & 0.0269 & 1.005 & 0.0273 & 1.006 & 0.0248 & 1.000 & 0.0269 & 1.006 & 0.0393 & 1.001 \\
\hline 3 & 0.0237 & 1.005 & 0.0235 & 1.005 & 0.0238 & 1.005 & 0.0216 & 1.000 & 0.0235 & 1.005 & 0.0346 & 1.001 \\
\hline 4 & 0.0214 & 1.004 & 0.0213 & 1.004 & 0.0216 & 1.004 & 0.0194 & 1.000 & 0.0212 & 1.004 & 0.0316 & 1.001 \\
\hline 5 & 0.0198 & 1.002 & 0.0197 & 1.002 & 0.0200 & 1.003 & 0.0180 & 1.000 & 0.0196 & 1.002 & 0.0296 & 1.001 \\
\hline 6 & 0.0187 & 1.001 & 0.0186 & 1.001 & 0.0188 & 1.001 & 0.0168 & 1.000 & 0.0185 & 1.001 & 0.0281 & 1.002 \\
\hline 8 & 0.0171 & 0.998 & 0.0170 & 0.998 & 0.0172 & 0.998 & 0.0153 & 1.000 & 0.0169 & 0.998 & 0.0263 & 1.002 \\
\hline 10 & 0.0161 & 0.996 & 0.0161 & 0.996 & 0.0162 & 0.996 & 0.0143 & 1.000 & 0.0159 & 0.995 & 0.0252 & 1.003 \\
\hline 15 & 0.0147 & 0.991 & 0.0147 & 0.991 & 0.0148 & 0.991 & 0.0130 & 0.999 & 0.0146 & 0.990 & 0.0238 & 1.003 \\
\hline 20 & 0.0141 & 0.987 & 0.0141 & 0.987 & 0.0142 & 0.987 & 0.0123 & 0.999 & 0.0139 & 0.986 & 0.0231 & 1.003 \\
\hline
\end{tabular}

Notes: *Ratio of linear absorption coefficient of CIRS sample to that of real-body tissues. ${ }^{10,11}$ Relative difference $(\%)=($ Ratio- $I) \times 100$.

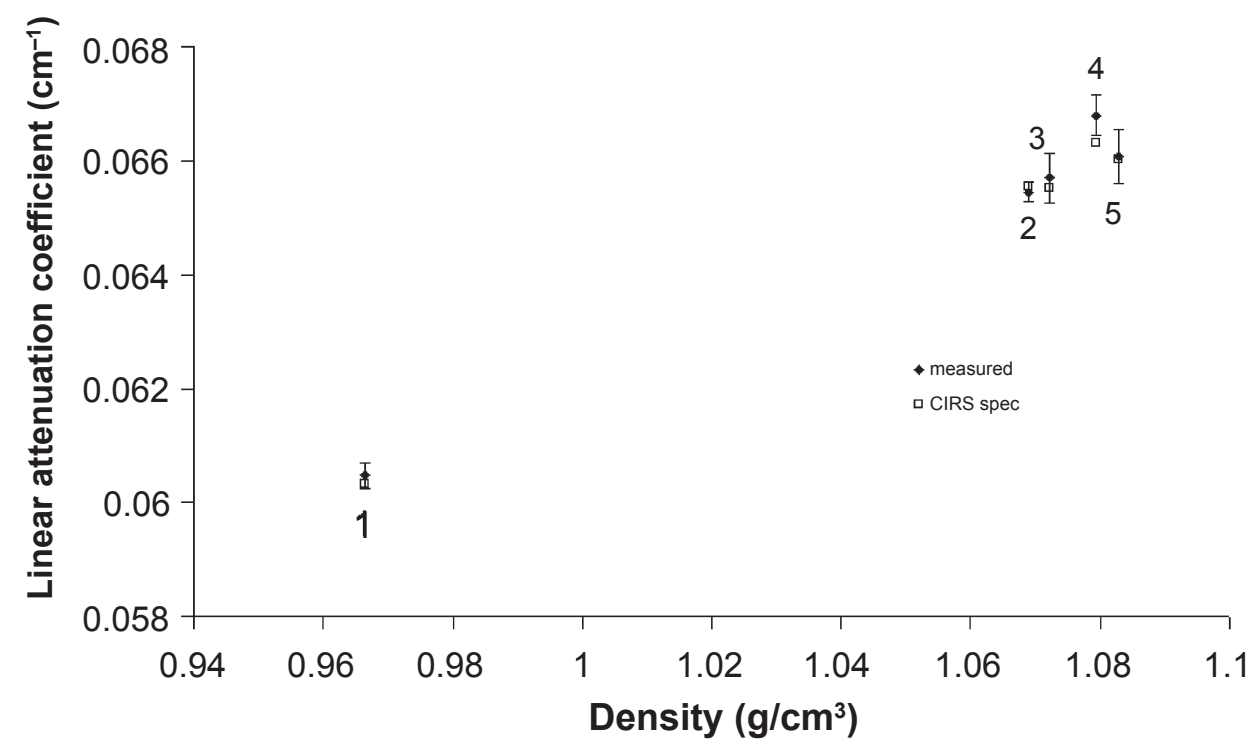

Figure 3 Measured linear attenuation coefficients for different tissue-equivalent resin samples in comparison with calculations (CIRS spec). The bone sample is not shown in order to emphasize what is happening at the soft tissue region. Error bars are one standard error of the mean. Labels: (I) Adipose; (2) Intestine; (3) Bladder; (4) Muscle; (5) Prostate. 


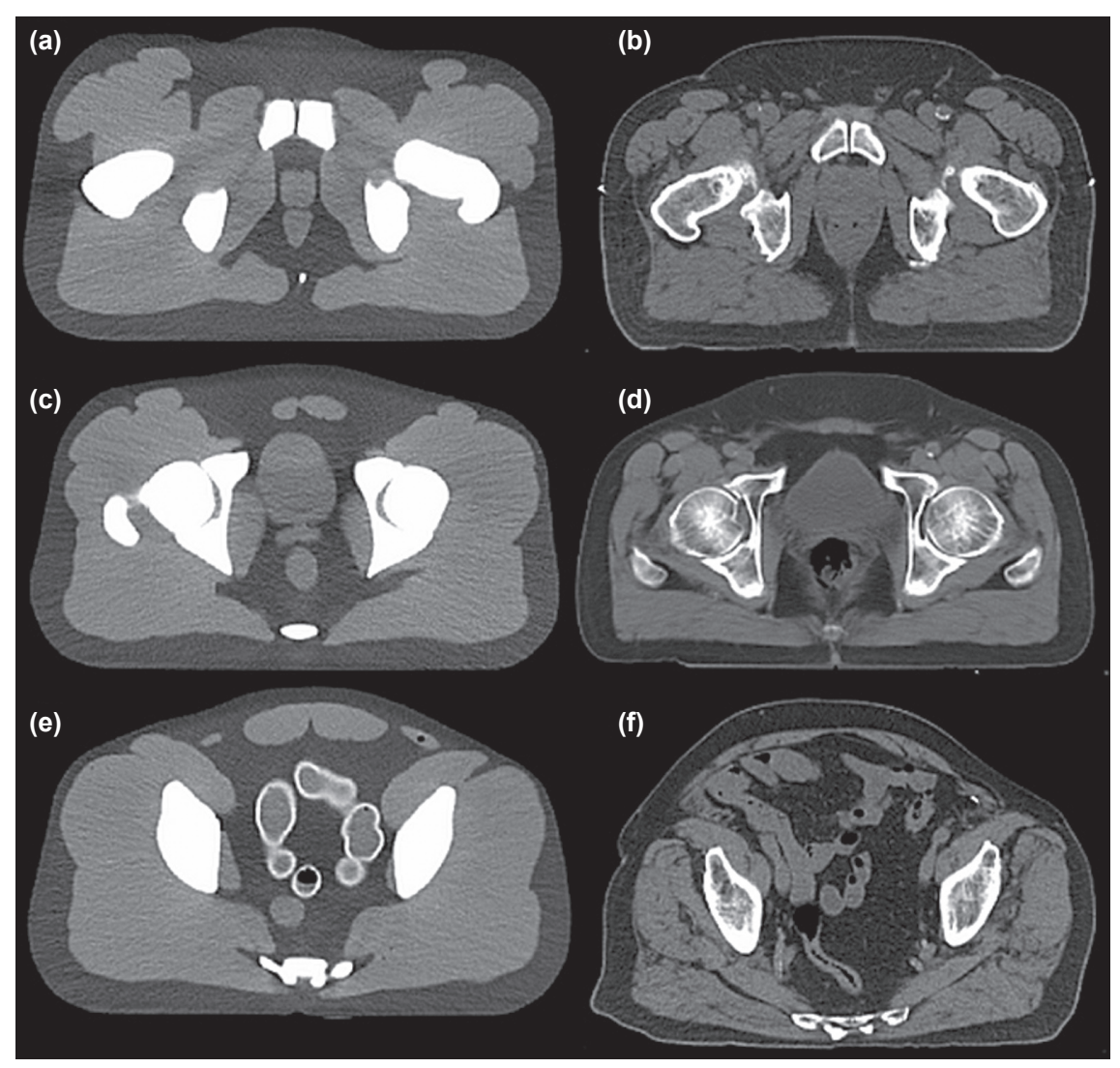

Figure 4 Comparison of axial computed tomography images of the phantom (a, c, e) and a selected prostate cancer patient (b, d, f). Images (a) and (b) show a more inferior slice including prostate and rectum. Images (c) and (d) show bladder, rectum, and seminal vesicles. Images (e) and (f) show a more superior slice including the intestines.

the entire organ without distinguishing the difference between the bladder wall and the urine content; (3) the solid bones, which should have a nonuniform density as in cortical and trabecular bones in real patients. Based on our study, artifacts due to photoelectric absorption in these solid bones are more pronounced for $\mathrm{kV}$ imaging (as compared to

Table 4 Summary of computed tomography (CT) numbers measured in phantom and in a patient population: $\left(^{*}\right)$ cortical bone, $\left({ }^{* *}\right)$ trabecular bone

\begin{tabular}{llll}
\hline Structure & $\begin{array}{l}\text { CT number } \\
\text { from CIRS } \\
(\mathbf{H U})\end{array}$ & $\begin{array}{l}\text { CT number } \\
\text { in phantom } \\
\text { (HU) }\end{array}$ & $\begin{array}{l}\text { CT number } \\
\text { in patients } \\
\text { (HU) }\end{array}$ \\
\hline Prostate & 38 & $21 \pm 19$ & $40 \pm 17$ \\
Bladder (urine) & 44 & $21 \pm 16$ & $14 \pm 16$ \\
Bladder (wall) & 44 & $21 \pm 16$ & $36 \pm 15$ \\
Adipose & -75 & $-69 \pm 14$ & $-102 \pm 15$ \\
Muscle & 49 & $53 \pm 14$ & $57 \pm 16$ \\
Intestine & 32 & $34 \pm 15$ & $38 \pm 16$ \\
Bone (average) & 867 & $813 \pm 23$ & $923 \pm 106 *$ \\
& & & $86 \pm 39 * *$ \\
\hline
\end{tabular}

MV imaging). We note here that, as a result of this study, the uniform-density issue of the solid bones has been addressed by CIRS in their newer version of the phantom.

We have shown that the images of the phantom gave a good indication on the quality of most patient images for a clinical MV-CBCT system. Thus, if the quality of phantom images obtained for a new X-ray imaging system is poor, then there is a good reason to believe that the image quality of the new X-ray system is not adequate for most patients. Thus, the phantom can be used as a screening tool for the identification of new X-ray systems that are not adequate for patient imaging in a radiotherapy department without the need to irradiate patients, which would be very useful during the commissioning of a new X-ray imaging system. Other than commissioning a new imaging system, the phantom can be used for quality assurance as well. For example, the phantom can be used in quality assurance procedures to test the accuracy of realignment of the "target of the day" to the treatment beams. In addition, the phantom is convenient for training radiation therapists in the use of online image registration software for localizing the prostate in cone-beam CT image-guided treatments. 

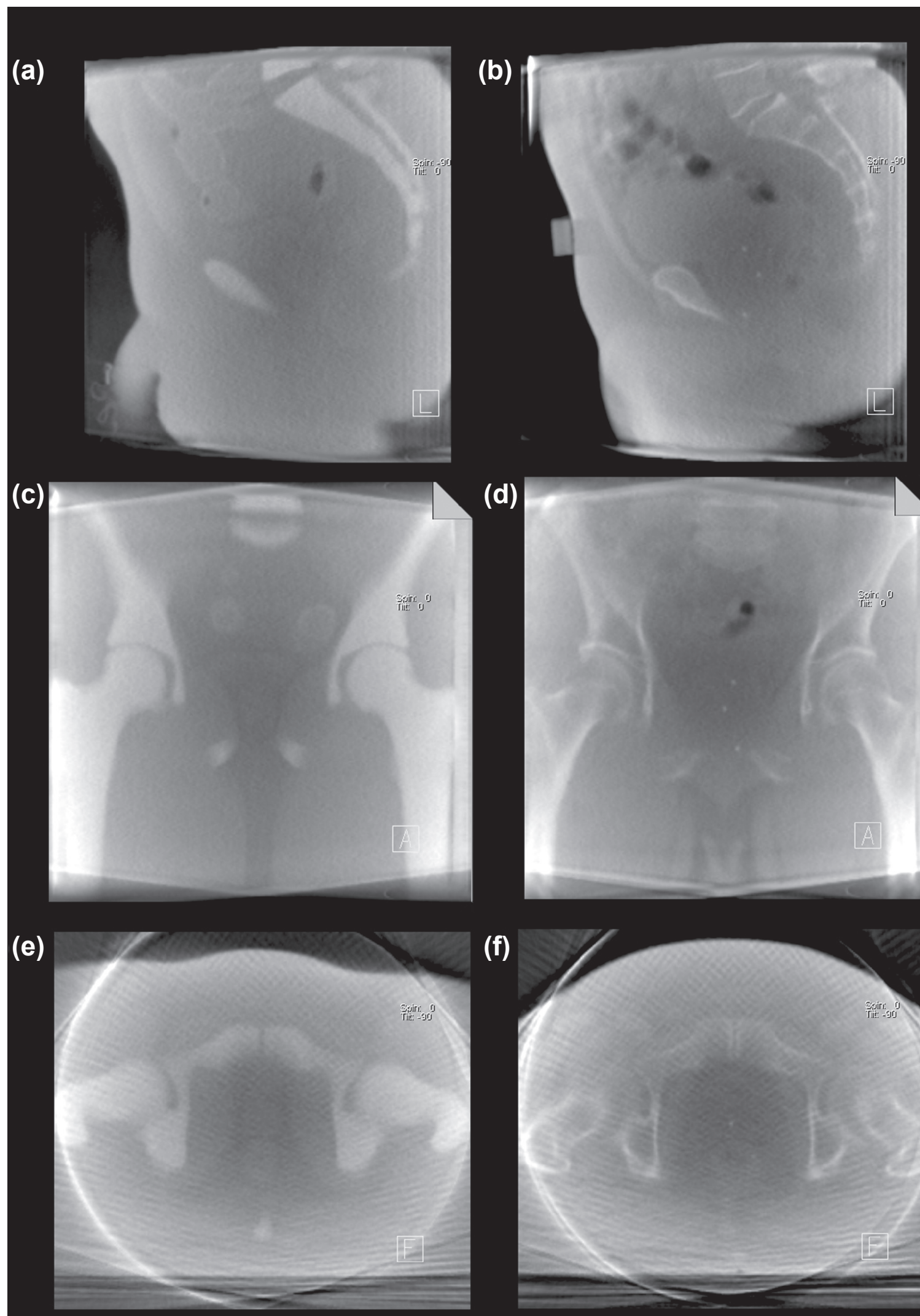

(d)

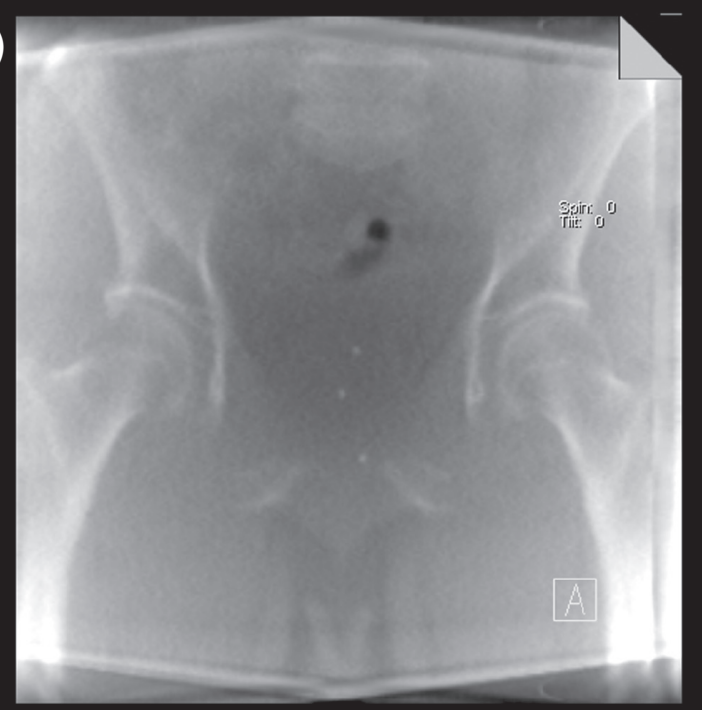

(f)

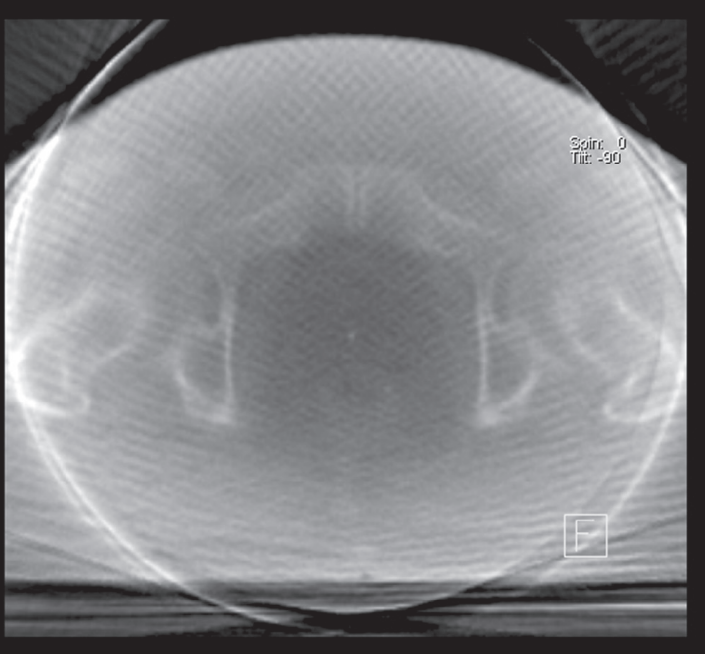

Figure 5 Comparison of MV-CBCT images of the phantom $(\mathbf{a}, \mathbf{c}, \mathbf{e})$ and a selected prostate cancer patient $(\mathbf{b}, \mathbf{d}, \mathbf{f})$ obtained using a clinical investigational MV-CBCT system. Only images in three principle planes, ie, sagittal $(\mathbf{a}, \mathbf{b})$, coronal $(\mathbf{c}, \mathbf{d})$, and transverse plane $(\mathbf{e}, \mathbf{f})$ through the center of the prostate are shown. Three gold markers implanted in the prostate of the patient are visible in images (b) and (d).The patient images shown here were obtained based on the work of Pang and colleagues. ${ }^{5}$ Abbreviation: $\mathrm{MV}-\mathrm{CBCT}$, megavoltage cone-beam computed tomography. 


\section{Conclusion}

A new anthropomorphic male pelvic phantom has been evaluated for radiotherapy applications. Our results demonstrated that the male pelvic phantom is a good representation of actual prostate cancer patients and can be a valuable tool for image-guided radiotherapy.

\section{Acknowledgments}

The authors would like to thank P Basran from Odette Cancer Centre for his help with CT scanning and H Gall from CIRS Inc. for his assistance in designing the phantom and revising the manuscript. This work was partially supported by Siemens Medical Systems, Inc. and the DoD Prostate Cancer Research Program Grant.

\section{References}

1. Langen KM, Jones DT. Organ motion and its management. Int J Radiat Oncol Biol Phys. 2001;50:265-278.

2. Jaffray DA, Siewerdsen JH, Wong JW, Martinez AA. Flat-panel conebeam computed tomography for image-guided radiation therapy. Int $J$ Radiat Oncol Biol Phys. 2002;53:1337-1349.

3. Pouliot J, Bani-Hashemi A, Chen J, et al. Low-dose megavoltage cone-beam CT for radiation therapy. Int J Radiat Oncol Biol Phys. 2005;61:552-560.

4. Seppi EJ, Munro P, Johnsen SW, et al. Megavoltage cone-beam computed tomography using a high-efficiency image receptor. Int $J$ Radiat Oncol Biol Phys. 2003;55:793-803.

5. Pang G, Bani-Hashemi, Au P, et al. Megavoltage cone beam digital tomosynthesis (MV-CBDT) for image-guided radiotherapy: A clinical investigational system. Phys Med Biol. 2008;53:999-1013.

6. Rajapakshe R, Luchka KB, Shalev S. A quality control test for electronic portal imaging devices. Med Phys. 1996;23:1237-1244.

7. Alderson SW, Lanzl LH, Rollins M, Spira J. An instrumental phantom system for analog computation of treatment plans. Am J Roentgenol Radium Ther Nucl Med. 1962;87:185-195.

8. Hood C, Kron T, Hamilton C, et al. Correlation of 3D-planned and measured dosimetry of photon and electron craniospinal radiation in a pediatric anthropomorphic phantom. Radiother Oncol. 2005;77:111-116.
9. National Institutes of Medicine. Bethesda, MA: United States National Library of Medicine Updated 2009 February 10; cited 2009 June 3. Available from: http://www.nlm.nih.gov/research/visible/ visible_human.html.

10. Woodard HQ, White DR. The composition of body tissues. Br J Radiol. 1986;59:1209-1219.

11. Snyder WS, Cook MJ, Nasset ES, Karhausen LR, Howells GP, Tipton IH. Report of the Task Group on Reference Man: ICRP 23. Oxford: Pergamon Press; 1975.

12. Seltzer SM. Calculation of photon mass energy-transfer and mass energy-absorption coefficients. Radiat Res. 1993;136:147-170.

13. Hubbell JH, Seltzer SM. Tables of X-ray mass attenuation coefficients and mass energy-absorption coefficients $1 \mathrm{keV}$ to $20 \mathrm{MeV}$ for elements $\mathrm{Z}=1$ to 92 and 48 additional substances of dosimetry interest. NISTIR 5632. National Institute of Standards and Technology internal report. Cited 2009 June 3. Available from: http://physics.nist.gov/PhysRefData/ XrayMassCoef/ElemTab/z74.html.

14. Johns HE, Cunningham JR. The Physics of Radiology. Springfield, IL: Thomas Books; 1983.

15. Persliden J, Carlsson GA. Scatter rejection by air gaps in diagnostic radiology. Calculations using a Monte Carlo collision density method and consideration of molecular interference in coherent scattering. Phys Med Biol. 1997:42:155-175.

16. Ozard SR, Grein EE. Analytical calculation of the portal scatter to primary dose ratio: an EGS4 Monte Carlo and experimental validation at large air gaps. Phys Med Biol. 2001;46:1719-1736.

17. Webb S. The Physics of Medical Imaging. London, UK: Institute of Physics Publishing; 1988.

18. Khan MF. The Physics of Radiation Therapy. Baltimore, MA: Williams \& Wilkins; 1994.

19. Roeske JC, Forman JD, Mesina CF, et al. Evaluation of changes in the size and location of the prostate, seminal vesicles, bladder and rectum during a course of external beam radiation therapy. Int J Radiat Oncol Biol Phys. 1995;33:1321-1329.

20. Antolak JA, Rosen II, Childress CH, Zagars GK, Pollack A. Prostate target volume variations during a course of radiotherapy. Int $J$ Radiat Oncol Biol Phys. 1998;42:661-672.

21. Mechalakos JG, Mageras GS, Zelefsky MJ, et al. Time trends in organ position and volume in patients receiving prostate threedimensional conformal radiotherapy. Radiother Oncol. 2002;62: 261-265.

22. Duerloo KE, Steenbakkers RJ, Zijp LJ, et al. Quantification of shape variation of prostate and seminal vesicles during external beam radiotherapy. Int J Radiat Oncol Biol Phys. 2005;61:228-238.
Reports in Medical Imaging

\section{Publish your work in this journal}

Reports in Medical Imaging is an international, peer-reviewed, open access journal publishing original research, reports, reviews and commentaries on all areas of medical imaging. The manuscript management system is completely online and includes a very quick and fair peer-review system, which is all easy to use.

\section{Dovepress}

Visit http://www.dovepress.com/testimonials.php to read real quotes from published authors. 